\title{
AN INTERDISCIPLINARY CONSERVATION MODULE FOR CONDITION SURVEY ON CULTURAL HERITAGES WITH A 3D INFORMATION SYSTEM
}

\author{
Corrado Pedelì
}

\author{
Superintendence for Cultural Heritage of Aosta Valley, Piazza Narbonne 3, 11100 Aosta, Italy - \\ c.pedeli@regione.vda.it
}

\begin{abstract}
KEY WORDS: condition assessment, decay mapping, database, 3D LASER scanning, photogrammetry. conservation project, archaeology.
\end{abstract}

\begin{abstract}
:
In order to make the most of the digital outsourced documents, based on new technologies (e.g.: 3D LASER scanners, photogrammetry, etc.), a new approach was followed and a new ad hoc information system was implemented. The obtained product allow to the final user to reuse and manage the digital documents providing graphic tools and an integrated specific database to manage the entire documentation and conservation process, starting from the condition assessment until the conservation/restoration work. The system is organised on two main modules: Archaeology and Conservation. This paper focus on the features and the advantages of the second one. In particular it is emphasized its logical organisation, the possibility to easily mapping by using a very precise 3D metric platform, to benefit of the integrated relational database which allows to well organise, compare, keep and manage different kind of information at different level. Conservation module can manage along the time the conservation process of a site, monuments, object or excavation and conservation work in progress. An alternative approach called OVO by the author of this paper, force the surveyor to observe and describe the entity decomposing it on functional components, materials and construction techniques. Some integrated tools as the "ICOMOS-ISCS Illustrated glossary ..." help the user to describe pathologies with a unified approach and terminology. Also the conservation project phase is strongly supported to envision future intervention and cost. A final section is devoted to record the conservation/restoration work already done or in progress. All information areas of the conservation module are interconnected to each other to allows to the system a complete interchange of graphic and alphanumeric data. The conservation module it self is connected to the archaeological one to create an interdisciplinary daily tool.
\end{abstract}

\section{INTRODUCTION}

Paper introduces for the first time an overview of a new 3D recording computer tool conceived to support the conservation process for cultural heritages, with particular reference to the archaeological sites, monuments, object, excavations and conservation work in progress. The tool named Ad Hoc Conservation Module integrates LASER scanning, photogrammetry and GPS technologies with a particular DBMS. Paper focus on the envisioning and on the logical architecture of the Conservation Module, on its functioning and on the advantages for users respect to existing "similar" approaches and other computer systems. In particular they are highlighted the advantages that the system offers, mainly in term of scientific and sharable data within interdisciplinary professional groups, during the conservation process: condition survey (or visual investigation), planning (or technical conservation project) and conservation work (or restoration).

The idea of this project was born from the need to make the most of digital outsourcing products, with particular reference to those based on 3D LASER scanner and photogrammerty.

We wanted to avoid that the this particular and expensive typology of documents become "armoured safes", inaccessible and unusable treasure for the operators. The main goal was to give the possibility to the archaeologists, conservators, restorers, drawers and others professionals, to reuse these document as a graphic base to elaborate news and different products.

The second important reason was to create an interdisciplinary computer tool, which reflect the different mental approaches, which allow to share and compare common digital documents and informations, to avoid dispersion and duplications, to interface different skills. Last but not least, we needs an combined recording tool, which integrate the graphic mapping functions with a specific databank (all in one).

The obtained product, both in term of project and implementation, represents a good example of a close cooperation between public and private subjects. The Superintendence for Cultural Heritage of Aosta Valley (IT) has actively contributed during project and implementation with Ad Hoc 3D Solution company (Aosta Valley - IT) which has developed the computer application.

Two different but specific know-how were combined.

Specific knowledge and skills acquired at international level, in the fields of conservation and information technology were shared and transferred to an innovative and, we hope, useful tools for the daily work and long-term management of Cultural Properties.

\section{State of art, needs and basic requirements}

The documentation based on images applied on cultural heritage, in particular for conservation purpose is a well known reality since log time.

They have been developed hundred of project and information systems which have the aim to map and document contexts, monuments or objects by using 2D o 3D computer technologies. A big number of these project, maybe too much, disappear after few years, other ones are never experimented on site. Its so rare to know the evolution and the progress of them, to understand the critical issues and first of all to experiment directly them. Unfortunately some of this project are only a business operation 
and they absolutely don't give any kind of contribution to the scientific world.

Among the more disappointed final users there are the conservators/restorers. They have a very pragmatic approach because they are used to focus on daily conservation problems and solutions, and they are stressed from emergencies and deadline.

Some of these would be accept to work supported by computer tools but under certain conditions: computer tools have to reflect their operational needs and their modus operandi, they have to be very intuitive, so they have to use a familiar terminology and process flow, finally they don't have to need a long learning period.

From a strategic point of view the documentation system based on images have to integrate high precision flexible graphic vector with a performed relational DBMS.

The traditional computer tools used in conservation usually are CAD or GIS based and they are considered more or less standard systems with which commonly is possible to map sites and monuments in 2D. In the last years, a relatively large number of 3D information systems was used in the field of cultural heritage. In particular, it is perceived a great interest, both technological and commercial, versus LASER or photogrammetric solutions which, commonly, are oriented towards on virtual reconstructions. Only a limited number of 3D information system are strictly devoted to conservation activities with particular reference to the condition assessment or survey phase. This is another crucial point which determine the success or the indifference for a computer tool by the operators which are normally trained for other purposes. They needs or they imagine to needs some user-friendly technology which don't require specific knowledge or training and finally that really support conservation process during all phases. In practice this means to dispose of something which really substitute graph paper, measurement tools, pencils and colours and it combines different interconnected functions (metric graphic, text, database, link to other documents, etc.) including the possibility to use the recorded data to implement further phases as conservation project and tracking conservation intervention along the time.

\section{THE AD HOC CONSERVATION MODULE}

Conservation Module exploits all the benefits that the Ad Hoc 3D System can offers: first of all the integration of different technologies as LASER scanning, photogrammetry and GPS, which allows to drawing a reliable metric map of the monument/object and decay patterns, with high resolution if needed (see also Bornaz 2013); secondly, an integrated and interdisciplinary conservation database which allows to document the complete conservation process, from the investigation to the intervention.

The Conservation Module is conceived as a practical daily tool to support conservators and restorers during the complete condition survey process for site, monuments and also objects. Its functions permit to implement the mapping and description of features and decay patterns, writing the conservation project and record the intervention.

Conservation Module combines a 3D metric mapping with an specific database. All information (measurements, plotting, etc.) are organized according to its correct 3D position. Then it can be queried using attributes, geometric characteristics or spatial position.
The database is conceived also to record and manage the conservation chronology. This means that the module become a true tracking system of conservation process.

Conservation Module is organised in four main information areas which are divided in several specific descriptive sections (Figure 1).

AD HOC SYSTEM FOR CULTURAL HERITAGE - LOGICAL ARCHITECTURE

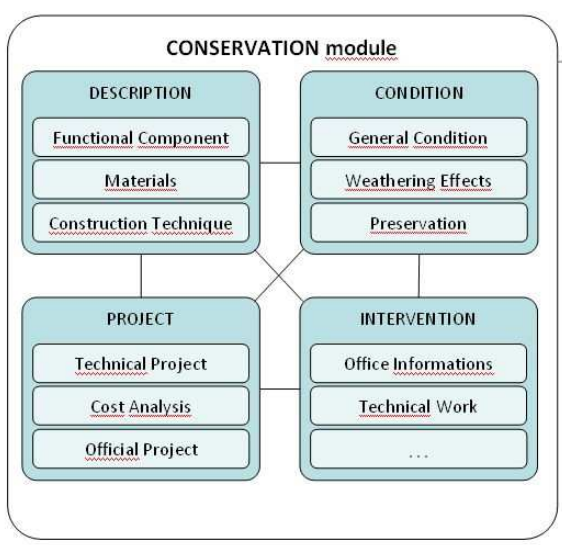

Figure 1. Scheme of Conservation Module organised in four "information areas" (light blue colour) and several "descriptive sections". Areas are interconnected and the "conservation module" can be related with the "archaeological module".

The Description area is conceived to describe visual features by different point of view and to combine different professional backgrounds. Its organisation is based on the approach called OVO (Organised Visual Observation) developed by the author of this article ${ }^{1}$. OVO organise the naked-eyes observation and facilitate the identification of each entity, the analysis of their features, then force the surveyor to define conceptual and physical interactions and dynamism of the system. Ad Hoc Conservation Module borrows the same principle to force user to map and record, in schematic and objective way most as possible, what he macroscopically is looking. Initially the users can draws different 3D metric maps above the same 3D orthophotos corresponding to different point of views (e.g.: different conservators, scientists, architects, others). In particular by using the "Functional Components" section it's possible to highlight arches, windows, columns, floors or walls or the handle and the blade of a knife in the case of an object. By using the "Materials" section instead is possible to map and describe the material constituent (i.e.: stone, wood, glass) and eventually connecting them with functional components. The A third point of view is provided by the "Construction Techniques" section in which is possible to draw map and describe parts (the same or other parts) of the monument/object focusing on its different construction typologies and chronological phases. This descriptive section is conceptually similar to another one included in the Archaeological Module (see Bornaz 2013) but it represents an alternative for other professional as architects, conservators or art historians.

Table 1 shows the simple database structure which manage either Functional Component, Materials and Construction Techniques sections.

Functional Components - Materials Constituents

\begin{tabular}{l|l} 
Name & the name assigned to the functional
\end{tabular}
component, e.g.: arch, column, etc. 


\begin{tabular}{|l|l|}
\hline Colour ref. & the colour used to map component \\
\hline Description & $\begin{array}{l}\text { general description of features of the } \\
\text { functional component from a macro } \\
\text { point of view }\end{array}$ \\
\hline Area & $\begin{array}{l}\text { measure of extension in cmq., dmq. or } \\
\text { mq. }\end{array}$ \\
\hline Length/Perimeter & $\begin{array}{l}\text { measure of length or perimeter of the } \\
\text { line or area drawn }\end{array}$ \\
\hline Images & $\begin{array}{l}\text { one or more picture of the functional } \\
\text { component (overview at low resolution) }\end{array}$ \\
\hline Documents & links to other related files \\
\hline Behavior & $\begin{array}{l}\text { role /functions carried out by the } \\
\text { function component, e.g.: it support roof, } \\
\text { it delimitate a square space, etc. }\end{array}$ \\
\hline $\begin{array}{l}\text { Physical } \\
\text { Connections }\end{array}$ & $\begin{array}{l}\text { spatial physical connections with others } \\
\text { functional component }\end{array}$ \\
\hline $\begin{array}{l}\text { Logical } \\
\text { Connections }\end{array}$ & $\begin{array}{l}\text { interpretative connections with the } \\
\text { surrounding context }\end{array}$ \\
\hline
\end{tabular}

Table 1. Functional Component and Materials Constituents sections. Resume of the fields provided by the integrated database.

The Condition area focus on the state of the preservation at the moment of surveying. In fact the conditions can change during the time, for example before and after conservation treatment or simply after some years of exposure. For this reason the "Condition area" allows to create an unlimited number of condition reports which are automatically and chronologically organised by Ad Hoc 3D System.

The graphic tools allows to map patterns of alteration and decay in metric way, if necessary with a precision of $1 / 10$ of millimetre for small objects or details of structures. Because of the mapping is always carried out in 3D it's possible to measure both extension and volume of the decay pattern (e.g.: gap or encrustation). For the same reason, the "linear-like" measurements (e.g.: joints length of the wall) can be done by using simple or projected line.

Data can be recorded approaching in different ways, as in the "Description area". General or preliminary information referred to the context as a whole (site, monument or object) can be recorded by using traditional and "progressive" text way within the "General Condition" section. A more structured and scientific tools instead are provided on "Weathering Effects" section. Here, deterioration patterns can be drawn and documented both in descriptive form or in schematic and organised way. Database can includes a number of selected standard or personalised decay glossaries. For the moment the implemented release provides the "Illustrated glossary on stone deterioration patterns" edited and published by the International Scientific Committee for Stone (ICOMOS-ISCS 2008) of which are respected the structure and terminology with some computer adaptations. Figure 2 shows a screenshot of a Weathering Effect editing form. A singular combination of ICOMOS Illustrated glossary with other scheme (Heinrichs, Fitzner 1999) allow to define a relative percentage of each decay pattern.

Finally "Preservation" section is conceived to record and document information about some other useful parameters concerning future preservation as the vulnerability of the site/monument or object, the risks for short, medium and long time. A space for recommendations it is also included.

The Project area is still in progress. Nevertheless the project foresees that the area is organized in three descriptive sections. Within the "Technical Project" section the conservator/restorer can describe in detail all the conservation technical operations which are predictable for intervention: what to do, how to do it and in which sequence to do it. All the operation can be related to a specific functional component or material if mapped before. This very useful function allows to estimate in term of measurement the extension of each operation and its cost. A special "Cost analysis" section is also devoted to this important field, also to check the feasibility of the technical project. Finally, a more official section is foreseen in order to reorganise the executive project in formal way for public tenders for the award.

The Intervention area has been implemented to record in detail all kind of information useful to mange one or more conservation/restoration work during the time. This area is strictly related with the "Project area", especially with "Technical Project" section in order to control the correspondence between theoretical project and real work. To optimize the data entry session it's possible to import operations already recorded from the "Technical Project" and eventually modify them if some variation occur during the conservation work. Other logical link aimed to underline and manage chronological significance between different condition profiles, different projects or different conservation works, can be done. The Intervention area is based on a rich database organised in two main sections: "Office Informations" and "Technical Work". The first one provides the fields useful to track and manage along the time the intervention in progress (references to administrative documents, foreseen costs, timing, progress, professionals involved, security plan, etc.).

The technical section is divided in few subsections: the first one resume the complete conservation work implemented listing the main phases and the relative timeline. A central detailed subsection allows to describe in depth and structured way both phases and single operations, including detail about materials and techniques adopted, sequence and chronology of each operation or simply preliminary tests, the aim of each operation, the obtained results and the eventual criticisms. Finally each step of the intervention can be documented including an endless number of images and attached files path.

A final recommendation subsection which is linked to "Preservation section" of the "Condition area" complete the intervention report. The Intervention area should be theoretically the last information area to use if the conservation process followed a logical sequence (description > condition > project $>$ intervention). Anyway, because in practice in the world exist and have to be accepted different approaches and operational process, the architecture of the Ad Hoc Conservation Module allows to record interventions even if any information has been recorded before within other informative areas. In this case user cannot overwork previous graphic and alphanumeric data but it has to draw and describe ex novo the single operations of the intervention ...not so bad!. 


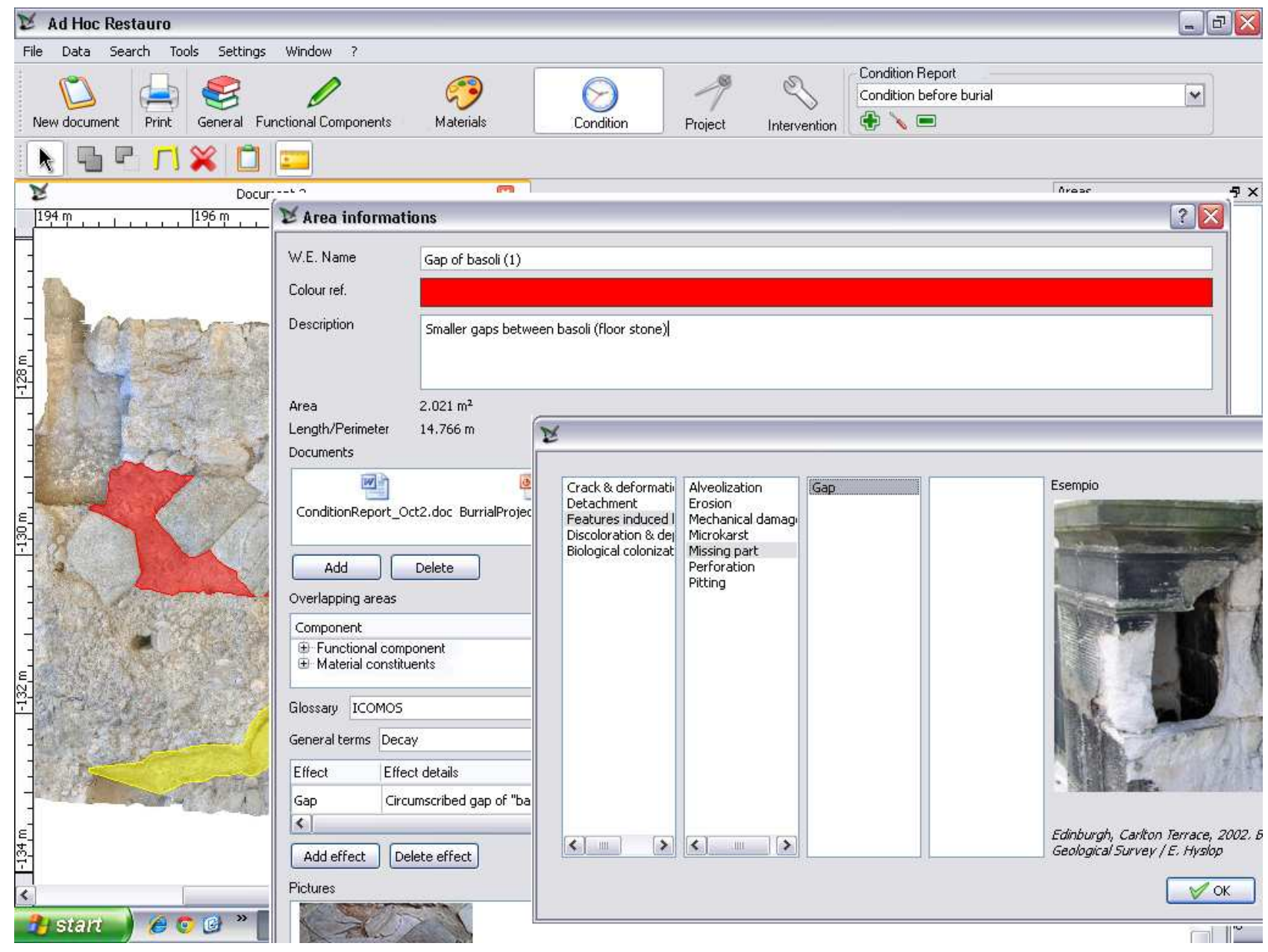

Figure 2. "Condition" area / "Weathering Effect" section - behind frame: mapping decay patterns; middle frame: DB to record weathering effect; front frame: the ICOMOS-ISCS Illustrated Glossary included on database allow to select correspondent weathering effect.

\section{CONCLUSIONS}

The information technologies as the 3D LASER scanner and the Photogrammetry, offer a great number of proposal and solution for the world of the cultural heritages. However a few number of these are devoted to the documentation of conservation process. Rarely they are implemented for archaeological cases (sites, monuments and objects) which need of some special devices. Add to this, normally outsourcing digital products returned to the customer (e.g.: Superintendence for Cultural Heritage) become "armoured safes", inaccessible and unusable treasure for the scientific operators (archaeologist, conservators, architect, managers, etc.). The project presented in this paper and the related obtained results proves that it is possible to change the approach and then to satisfy different instances: the pure high tech research in the field of information technology, the business, but also the "simplest" needs of professionals that daily operate on site balancing our pragmatic approach with the pressing and emerging technologies, trying to find some real benefit from them.

The Conservation Module implemented with the combined technology provided by Ad Hoc System effectively permit to reuse digital product for measurement, assessment, project, management in the field of cultural heritage. It can become a daily tool which support the entire conservation process at every stage, from a technical and management point of view.
Very intuitive graphic functions are provided to describe in detail site, monument or object, to map with high precision decay patterns, to project the conservation future actions and finally to record conservation work. All the conservation process is tracked and managed by a relational specific database and the different information areas are interconnected between them. The interdisciplinary activity is facilitated because of the possibility to share alphanumeric data and graphics.

Only one critical point can be found by a final user like me on this "Paradisiacal" situation: Ad Hoc 3D System is not an open source application and for the moment it has provided to the customer as a final tool to use and exploit the digital elaborations. The metric precision of Ad Hoc can be ensured only by the combination and symbiosis of certain technologies within included, by human skills and by other context conditions. This means that Ad Hoc could work on "external" (visitors) LASER scanner and orthophotos, but in this case it would not be ensured the same metric precision.

That said, my unlimited optimism allows me to believe that the Ad Hoc Conservation Module (or at least its philosophy) can be used by many other surveyor so that it will be possible to study better solutions than those proposed until today. 


\section{REFERENCES}

Bornaz, L., 2013. A 3D information system for the documentation of archaeological excavations. In: Recording, Documentation and Cooperation for Cultural heritage, XXIV International CIPA 2013 Symposium, 2-6 September 2013, Strasburg, France.

Heinrichs, K., Fitzner, B., 1999. Comprehensive characterization and rating of the weathering state of rock carved monuments in Petra/Jordan - Weathering forms, damage categories and damage index. In: Annual of the Department of Antiquities of Jordan, XLIII, Amman, pp. 321-351.

ICOMOS-ISCS, 2008. Illustrated glossary on stone deterioration patterns. Champigny/Marne, France.

Lagerqvist, B., 1999. A System Approach to conservation and cultural resources management. Photogrammetry as a base for designing documentation models. In: Mapping and Preservation for the new millennium, 3-6 October 1999, Olinda, Brasil. Brasilian Society of Cartography, Geodesy, Photogrammetry and remote Sensing (SBC).

Pedelì, C., Pesciarelli, R., 1997. ArkeoKeeper ${ }^{\circledR}$ : a computer recorder and controller of conservation and restoration work on the archaeological mobil finds", In: $8^{\text {me }}$ journée d'étude "Informatique e Conservation-Restauration $d u$ Patrimoine Culturel, Chalon-Sur-Saône, France; SFIIC.

Pedelì, C., 2005a. I restauri pilota della cinta muraria di Aosta: criteri di progettazione e metodologia operativa. In: Bollettino $n$. 2 della Soprintendenza per le Attività e i Beni Culturali della Regione Autonoma Valle d'Aosta. Edito da Regione Autonoma Valle d'Aosta, pp. 166-170.

Pedelì, C., 2005b. Guideline for Weathering Effects Observation and Recording on stone and related materials. Documentation for ICCROM courses (unpublished).

Pedelì, C., 2005c. "Comparative Glossary of the Weathering Effects on stone and related materials". Documentation for ICCROM courses (unpublished).

Pedelì, C., 2008. Indagine preliminare sul Chiostro Piccolo: stato di conservazione dell' apparato decorativo e ispezione del contesto. In: Atti del Convegno "La Certosa di Pavia e il suo Museo, Ultimi restauri e nuovi studi, 22-23 giugno 2005, Centro Congressi della Certosa di Pavia, Direzione regionale per i beni culturali della Lombardia, Milano, pp.305-319.

Roff, J. T., 2003. UML ${ }^{\mathrm{TM}}$ : A Beginner's Guide. McGraw-Hill.

\section{Acknowledgements}

I wish to thanks Leandro Bornaz (Ad Hoc 3D Solutions s.r.l.) and his collaborators for the availability offered to me and to the Superintendence for Cultural Heritage of Aosta Valley (IT) during the phases of analysis, envisioning and project of the Conservation Module.
Notes

1 OVO (Organised Visual Observation) is a combination of several methodologies extrapolated from cognitive sciences and information technology (IT). The OVO approach has been developed by Corrado Pedelì for training practical sessions on system approach in the field of condition survey of archaeological sites, especially when working with the interdisciplinary professional groups. OVO conceives an archaeological context, a monument or an object as a dynamic system that can be logically decomposed into subsystems and simplest entities. Done that each of these can be isolated, characterised with attributes and behaviours, drawn and finally linked among them to form a new conceptual model. OVO was experimented during several years especially for ICCROM courses and then implemented in different countries of Middle Est, South-Est Europe, Asia and Europe). 